\title{
IMPROVED HYPOXIA MODELING FOR NUTRIENT CONTROL DECISIONS IN THE GULF OF MEXICO
}

\author{
Shahid Habib ${ }^{1}$, Ken Pickerring ${ }^{1}$, Maria Tzortziou ${ }^{2,}{ }^{1}$, Antonio Maninio ${ }^{1}$, Fritz Policelli ${ }^{1}$, Jeff Stehr ${ }^{2}$ \\ ${ }^{1}$ NASA Goddard Space Flight Center, Greenbelt, Maryland \\ ${ }^{2}$ University of Maryland, College Park, Maryland
}

\begin{abstract}
The Gulf of Mexico Modeling Framework is a suite of coupled models linking the deposition and transport of sediment and nutrients to subsequent bio-geo chemical processes and the resulting effect on concentrations of dissolved oxygen in the coastal waters of Louisiana and Texas. Here, we examine the potential benefits of using multiple NASA remote sensing data products within this Modeling Framework for increasing the accuracy of the models and their utility for nutrient control decisions in the Gulf of Mexico. Our approach is divided into three components: evaluation and improvement of (a) the precipitation input data (b) atmospheric constituent concentrations in EPA's air quality/deposition model and (c) the calculation of algal biomass, organic carbon and suspended solids within the water quality/eutrophication models of the framework.
\end{abstract}

Index Terms - Remote Sensing, Modeling, Nitrogen, Air pollution, Sea coast.

\section{INTRODUCTION}

The largest hypoxic zone currently affecting the United States, and the second largest hypoxic zone worldwide, occurs in the northern Gulf of Mexico, adjacent to the Mississippi River on the Louisiana/Texas continental shelf. It forms each summer and can extend up to 80 miles offshore, stretching from the discharge of the Mississippi River westward to coastal waters of Texas. Hypoxic water supports fewer organisms and has been linked to massive fish kills in the Gulf of Mexico, reduction of biodiversity, disruption of ecosystems, depletion of fisheries, and loss of habitat for less mobile animals such as crabs and mussels. The size of the Gulf of Mexico hypoxic zone varies considerably each year with a maximum areal extent of $22,000 \mathrm{~km}^{2}$, approximately the size of the state of Massachusetts, during the summer of 2002.

As required by the Harmful Algal Bloom and Hypoxia Research Control Act of 1998, the Mississippi River/Gulf of Mexico Watershed Nutrient Task Force issued the 2001 Gulf Hypoxia Action Plan (updated in 2008) for reducing, mitigating, and controlling Hypoxia in the Northern Gulf of Mexico. According to the Gulf Hypoxia Action Plan, the goal is to reduce the hypoxic zone to less than $5,000 \mathrm{~km}^{2}$ by year 2015. While it is recognized in the Gulf of Mexico Hypoxia Action Plan that this is an extremely ambitious goal unlikely to be achieved in the prescribed time frame without significant additional resources, it is clear that actions taken in this direction can be expected to provide major benefits to the economic value of the Gulf of Mexico fisheries estimated to have been on the order of $\$ 744$ million per year in 2001 findings [1].

In response to the Gulf Hypoxia Action Plan, the EPA Gulf of Mexico Hypoxia Modeling and Monitoring Project has established a detailed modeling framework for the Mississippi-Atchafalaya River Basin which provides a capability to forecast the multi-source nutrient loading to the Gulf and the subsequent bio-geochemical processes leading

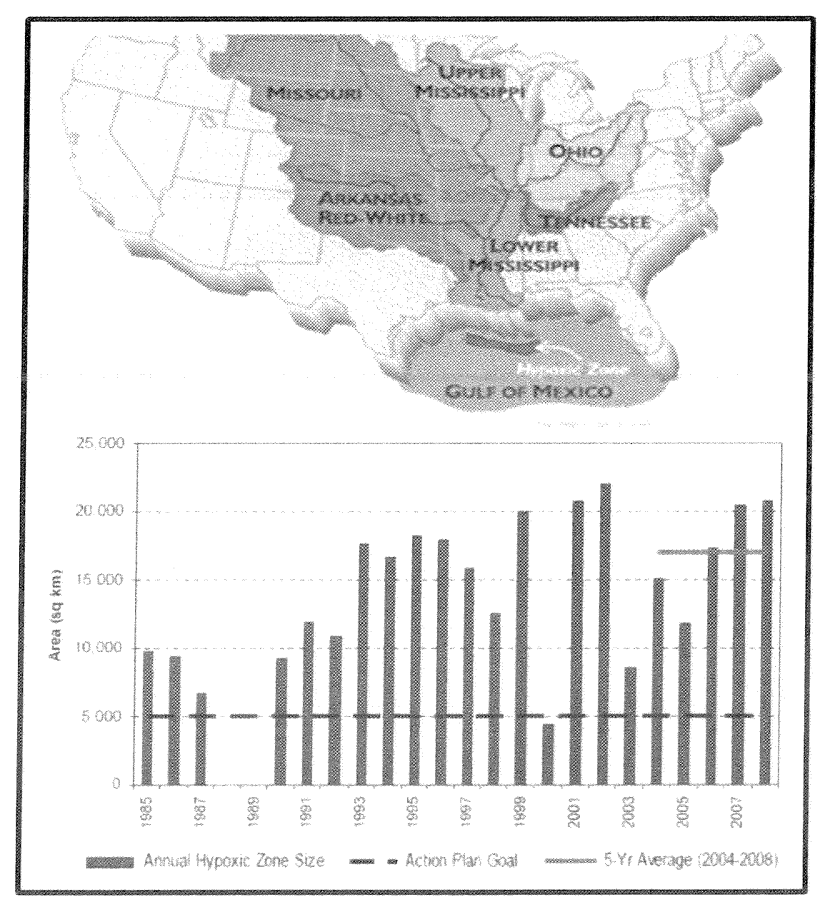

Figure 1: Gulf of Mexico hypoxic zone and changes in its areal extent during 1985-2008 (data from Louisiana University Consortium). 
to hypoxic conditions and subsequent effects on Gulf habitats and fisheries. The primary purpose of the EPA modeling framework is to characterize the impacts of nutrient management actions, or proposed actions, on the spatial and temporal characteristics of the Gulf hypoxic zone. The model is expected to play a significant role in determining best practices and improved strategies for incentivizing nutrient reduction strategies, including installation of on-farm structures to reduce sediment and nutrient runoff, use of cover crops and other agricultural practices, restoration of wetlands and riparian buffers, improved waste water treatment and decreased industrial nitrogen emissions. These decisions are currently made in a fragmented way by federal, state, and local agencies, using a variety of small scale models and limited data.

Our main objective in this work is to improve the scientific basis for management of nutrients and sediments in the Gulf of Mexico basin by increasing the accuracy of the EPA's Gulf of Mexico Modeling Framework through the use of NASA remote sensing Earth Observations. Use of NASA satellite data products in the model and for long term validation of the model has the potential to significantly increase the accuracy and therefore the utility of the model for decision making. The project is a joint partnership between NASA and EPA.

\section{OVERALL CONCEPT/ARCHITECTURE}

Multiple NASA products [5] (Fig. 2 and Table 1) are used to improve the EPA's Gulf of Mexico Modeling Framework (Gulf of Mexico Hypoxia Modeling and Monitoring, http://www.epa.gov/med/grosseile_site/gom.html). Satellite sensors include MODIS (Moderate-Resolution Imaging Spectrometer) on Terra and Aqua satellites, CALIOP (Cloud-Aerosol Lidar with Orthogonal Polarization) on the Calipso satellite, SeaWIFS (Sea-viewing Wide Field-ofview Sensor) on SeaStar, OMI (Ozone Monitoring Instrument) on Aura, and TRMM (Tropical Rainfall Measuring Mission) Microwave Imager (TMI) and Precipitation Radar (PR).

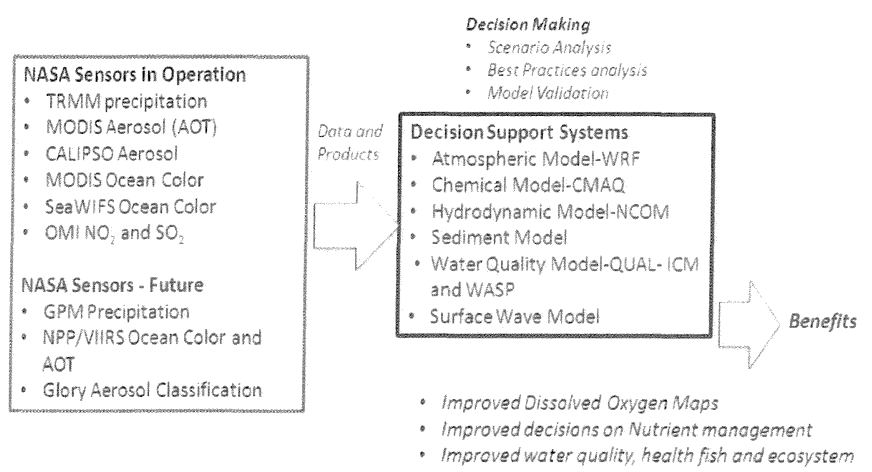

Figure 2: Enhancing EPA's decision support system using NASA satellite products.

\section{USE OF NASA SATELLITE DATA}

Our approach to enhance the EPA's Modeling Framework is divided into three components: evaluation and improvement of (a) the precipitation input data (b) atmospheric constituent concentrations in EPA's air quality/deposition model and (c) the calculation of algal biomass, organic carbon and suspended solids within the water quality/eutrophication models of the framework.

\subsection{Precipitation}

The Gulf of Mexico Hypoxia Modeling Framework uses model precipitation estimates from the regional model WRF (Weather and Research Forecasting model) as input to the atmospheric chemical transport and deposition model (CMAQ: Community Multiscale Air Quality model). We evaluate these model precipitation estimates using gridded precipitation observation products from NOAA and NASA. Over the continental United States the NOAA/National Weather Service Multisensor Precipitation Estimator (MPE) product is used. MPE combines precipitation observations from over 6000 rain gauges, 160 Doppler radars, and multiple IR and microwave satellite sensors. Satellite estimates are based on GOES IR and microwave products from the Defense Meteorological Satellite Program SSM/I instrument and the AMSU-B on the operational NOAA polar orbiting platforms. All of these sources of precipitation data have advantages and disadvantages. The MPE algorithm generates a gridded precipitation field using a single optimal estimation technique at 1 -hour and $4-\mathrm{km}$ temporal and spatial resolution. MPE does not provide sufficient coverage over the Gulf of Mexico for the hypoxia project. Therefore, we also use the NASA TMPA product. While the primary data are from satellite microwave and infrared sensors, data from the TRMM precipitation radar and rain gauges are used for calibration. Validation results have shown good performance at monthly time scales and for detecting large daily events. TMPA has lower skill in specifying light rain events over short intervals.

The Parameter-elevation Regressions on Independent Slopes Model (PRISM) [4] is also used to evaluate meteorological outputs from WRF. PRISM interpolates between station-based observations of precipitation and other meteorological variables using a digitized elevation model and assuming that local differences in precipitation and temperature are primarily driven by differences in elevation, but accounting for other factors. PRISM data are produced on a regularly spaced grid (in this case, $4 \mathrm{~km}$ ). Preliminary comparisons between WRF output and PRISM data are shown in Figure 3 for January and July 2006. Relatively good overall agreement is observed for both magnitude and location of precipitation over the Gulf of Mexico watershed area. However, the model seems to overestimate precipitation over Louisiana and Mississippi 
Table 1: NASA atmospheric and ocean color measurements, frequency and resolution.

\begin{tabular}{|c|c|c|c|c|}
\hline Satellite products & Satellite Sensor & Product Resolution & Frequency & Expected Benefits \\
\hline $\mathrm{NO}_{2}$ & OMI & $0.25^{\circ} \times 0.25^{\circ}$ & Once per day & \multirow{4}{*}{$\begin{array}{l}\text { Apply satellite data of } \\
\text { atmospheric } \mathrm{SO} 2, \mathrm{NO} 2 \\
\text { concentrations and aerosol } \\
\text { levels for improving } \\
\text { estimates of both wet and } \\
\text { dry deposition }\end{array}$} \\
\hline $\mathrm{SO}_{2}$ & OMI & $0.25^{\circ} \times 0.25^{\circ}$ & Once per day & \\
\hline $\begin{array}{l}\text { Aerosols Vertical } \\
\text { Profile }\end{array}$ & CALIPSO & Vertical: $30-60 \mathrm{~m}$ & $\begin{array}{l}\text { Approx once } \\
\text { per day }\end{array}$ & \\
\hline $\begin{array}{l}\text { Aerosols Optical } \\
\text { Thickness }\end{array}$ & MODIS & $10 \times 10 \mathrm{~km}$ & Twice per day & \\
\hline Precipitation & $\begin{array}{l}\text { NOAA Multisensor } \\
\text { Precipitation Estimator }\end{array}$ & $4 \mathrm{~km} \times 4 \mathrm{~km}$ & Hourly & \multirow{2}{*}{$\begin{array}{l}\text { Contribute to an improved } \\
\text { estimation of the wet } \\
\text { deposition of nutrients } \\
\text { within the model } \\
\text { framework, especially for } \\
\text { nitrogen compounds. }\end{array}$} \\
\hline Precipitation & $\begin{array}{l}\text { TRMM TMI and PR } \\
\text { multisensor calibrated } \\
\text { product-TMPA }\end{array}$ & $0.25^{\circ} \times 0.25^{\circ}$ & $\begin{array}{l}\text { Every } 3 \text { hour } \\
\text { nearreal time }\end{array}$ & \\
\hline $\begin{array}{l}\text { Ocean Color } \\
\text { (e.g. Chl-a, POC, } \\
\text { DOC, TSS, CDOM) }\end{array}$ & MODIS - Aqua & $-1 \mathrm{~km}$ Nadir & Every $1-2$ days & \multirow{2}{*}{$\begin{array}{l}\text { Validate the calculation of } \\
\text { photosynthetically active } \\
\text { biomass within the } \\
\text { modeling framework as well } \\
\text { as particulate and dissolved } \\
\text { organic carbon. }\end{array}$} \\
\hline $\begin{array}{l}\text { Ocean Color } \\
\text { (e.g. Chl-a, POC, } \\
\text { DOC TSS, CDOM) }\end{array}$ & SeaWIFS & $-1.1 \mathrm{~km}$ Nadir & Every $1-2$ days & \\
\hline
\end{tabular}

during the summer month. Further comparisons with satellite data may suggest improvements to the model which might include changing convective parameterization or cloud/precipitation microphysical scheme.

\subsection{Atmospheric Chemistry}

The Community Multiscale Air Quality (CMAQ) model simulates the linkage between emissions, meteorological transport, chemical concentrations and deposition over a continental-scale region [3]. Model inputs include chemical emissions and a representation of the atmosphere from a numerical weather simulation model. EPA is performing simulations over the Continental United States and the Gulf of Mexico region for year 2006. Emissions are generated using the SMOKE emissions processing system. Year 2006 specific emissions data for motor vehicles are from the EPA MOBILE 6 emission factor model. Power plant emissions are from the EPA Continuous Emission Monitors. Fire emissions are derived from space-based detections of fire counts coincident with the time of the simulation. Biogenic volatile organic carbon and NOx emissions are simulated using BEIS v.3.13 [7] and are derived using the same meteorological fields as the air quality simulations. All other emission sources are extrapolated from the 2005 National Emission Inventory.

Because $\mathrm{NO}_{2}$ is the critical species in determining the nitrogen deposition, we evaluate the CMAQ column amounts of $\mathrm{NO}_{2}$ using tropospheric column $\mathrm{NO}_{2}$ observations from the OMI sensor on NASA's Aura satellite. $\mathrm{NO}_{2}$ is the most robust among OMI tropospheric trace gas products, determined in an atmospheric transmission window with little interference from other pollutants. Total slant column $\mathrm{NO}_{2}$ is accurately measured, and the tropospheric vertical column is computed by subtracting the stratospheric component, and adjusting the Air Mass Factor using global model prescribed vertical profiles. Sulfate ion is typically the largest contributor to acidity, and $\mathrm{SO}_{2}$ gas is the precursor for sulfate. Thus. tropospheric column $\mathrm{SO}_{2}$ amounts derived from CMAQ are also compared with those measured by OMI.

Aerosol extinction optical depth (AOD) is measured twice daily by MODIS instruments on NASA's Terra and Aqua satellites. These observations are used in evaluating the CMAQ aerosol loading. The aerosol fields from CMAQ are also evaluated using vertical information on aerosol distributions from the CALIOP sensor.

\subsection{Water Quality/Biogeochemistry}

The extent of hypoxia in the Gulf of Mexico is a function of the amount of nutrients and organic matter that is delivered to these coastal waters and sinks to the ocean bottom layer. Satellite derived measurements of the amount of organic matter present as particulate organic carbon (POC), chlorophyll, dissolved organic carbon (DOC) and total suspended solids (TSS) in surface waters of the Gulf of Mexico are, thus, critical for remote sensing monitoring of hypoxic conditions. We compare these satellite products with output from the EPA's Water Quality Fate and Transport Model (WASP, CE-QUAL-ICM) to assess how well the model is performing and suggest areas of improvement. Level 1 SeaWiFS and MODIS sensor data have been processed to level 2 using up-to-date versions of SeaDAS and IDL along with all the required masking [2] [6]. Measurements were processed using existing algorithms for chlorophyll, distributed by the NASA Ocean Biology Processing Group (OBPG), and for POC [8]. Field measurements (e.g. Chl-a, DOC, POC, TSS concentrations) collected in the Gulf of Mexico by the EPA Gulf Breeze Lab 

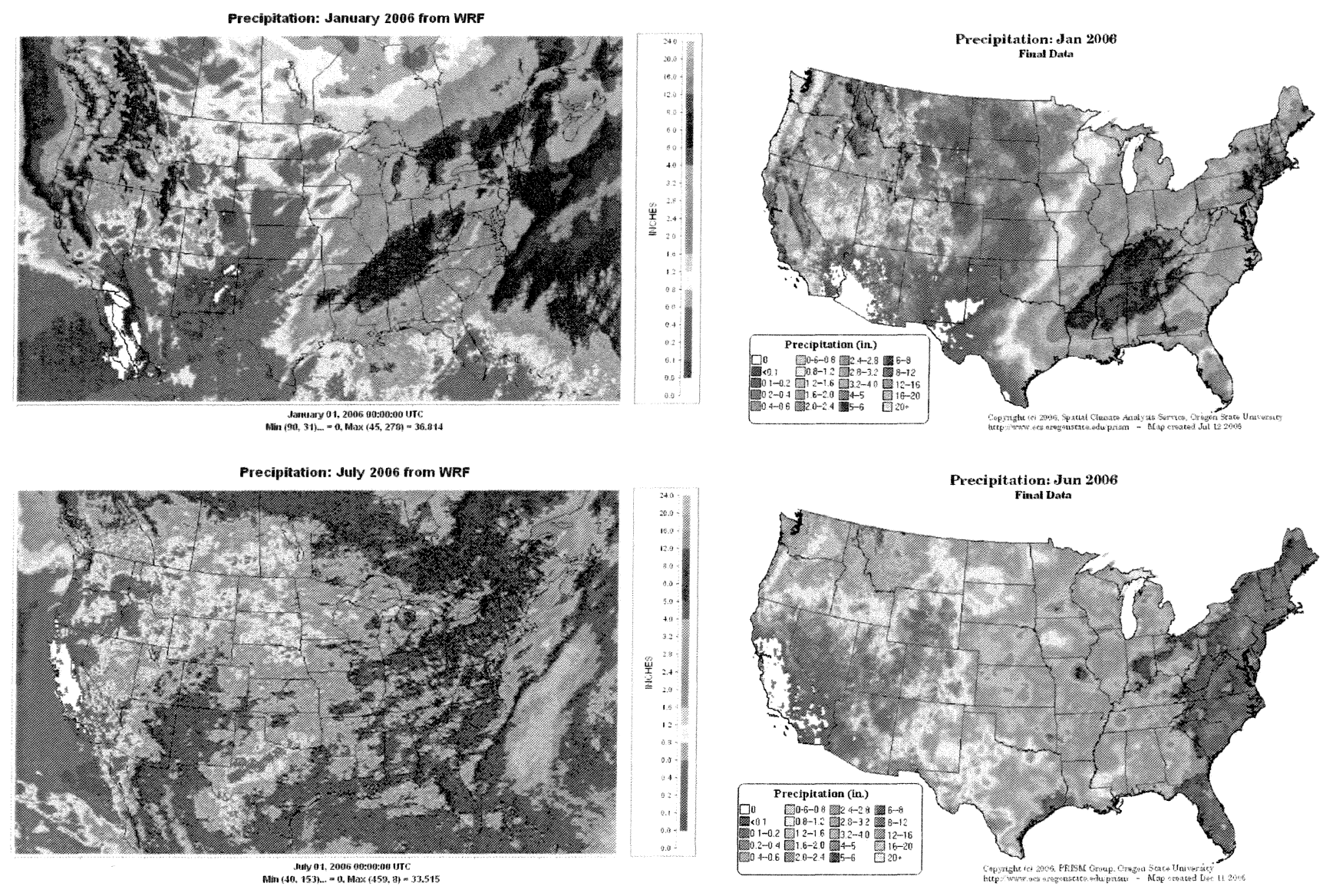

Figure 3: Model WRF estimates (left panels) and PRISM measurements (right panels) of precipitation over the US, for January (upper panels) and July (lower panels) of 2006.

will be applied to the validation and refinement of MODIS and SeaWiFS algorithms for improved estimates of biogeochemical variables in the study region.

\section{REFERENCES}

[1] C.M. Adams, E. Hernandez, and J.C. Kato, "The economic significance of the Gulf of Mexico related to population, income, employment, minerals, fisheries and shipping", Ocean and Coastal Management, 47, pp. 565$580,2004$.

[2] S.W. Bailey, and P.J. Werdell, "A multi-sensor approach for the on-orbit validation of ocean color satellite data products", Remote Sens. Environ., 102, pp 12-23, 2006.

[3] D.W. Byun, and K.L. Schere, "Review of the governing equations, computational algorithms, and other components of the Models-3 Community Multiscale Air Quality (CMAQ) modeling system", Applied Mechanics Reviews, 59, pp. 51-77, 2006.

[4] C. Daly, G.H. Taylor, and W.P. Gibson, "The PRISM approach to mapping precipitation and temperature",
Preprints, 10th Conf. on Applied Climatology, Reno, NV, Amer. Meteor.Soc., 10-12, 1997.

[5] S. Habib, "Utilizing Earth Science Observations for Applied Research", Asian Journal of Geoinformatics, Volume 9, No. 1, ISSN 1513-6728, March 2009.

[6] A. Mannino, M.E. Russ, and S.B. Hooker, "Algorithm development for satellite-derived distributions of DOC and CDOM in the U.S. Middle Atlantic Bight". J. Geophys. Res., 113, C07051, doi:10.1029/2007JC004493, 2008.

[7] D. Schwede, G. Pouliot, and T. Pierce, "Changes to the Biogenic Emissions Inventory System Version 3 (BEIS3)". In 4th CMAS Models-3 Users' Conference, Chapel Hill, North Carolina, USA, 2005.

[8] M. Stramska, and D. Stramski, "Variability of particulate organic carbon concentration in the north polar Atlantic based on ocean color observations with Sea-viewing Wide Field-of view Sensor (SeaWiFS). J. Geophys. Res. 110, C10018, doi:10.1029/2004JC002762, 2005. 